\title{
3 \\ KI HAJAR DEWANTARA, MENGURANGI PENGARUH BARAT SECARA KULTURAL
}

ISKANDAR WIRYOKUSUMO

\begin{abstract}
The entry of Western values, among others through culture, has been known recently. Cultural values are mostly among others enter through technology and consumer goods as product of technology. One attempt to balance values of the West, which would be cultural values, performed by Ki Hajar Dewantara, a National Cultural Educator once was. In an attempt balancing the efforts made on the basis of Javanese culture is more family-oriented, independence, a sense of moral high priority and live in harmony with nature. Many of the teachings of Java is developed through slogans and statements originating and noble values normative religious. So Western culture, such as individualistic, rationalistic, and intellectualism can be compensated fairly and naturally.
\end{abstract}

Keywords: Western values, Javanese culture, cultural values.

\section{PENDAHULUAN}

Ide-ide dan konsep-konsep pendidikan yang mengacu pada teori belajar "moderen" (modernism) sudah banyak dibicarakan dikalangan budayawan. Bahkan modernisme bergeser ke dasar filsafat posmodernisme sebagai hasil pendekonstruksian rasa tidak puas di kalangan pemikir dan pendidik yang melihat kegagalan modernisme ala barat. Pemikiran-pemikiran yang melandasi teori belajar itu menjadi indikator kegelisaan untuk memperoleh model pembelajaran yang ideal dan humanitis, khususnya model pembelajaran di Indonesia.

Hal ini bisa dimaklumi karena mungkin belum adanya penemuan-penemuan teori baru dalam bidang pendidikan yang berakar dari budaya bangsa Indonesia. Maksudnya belum temukan teori-teori Pendidikan Nasional,yang benar-benar bertolak dari akar Budaya Nesional. Dalam tulisan ini disajikan pikiran- pikiran KI Hajar Dewantara dalam usaha memberi dasardasar Teori maupun praktik Pendidikan, dengan dasar ajaran- ajaran Kultur Jawa. Usaha KI HAJAR Dewantara ini dapat diartikan sebagai pembendung dan sekaligus mengurangi pengaruh- pengaruh Barat.

Dalam sejarah Pendidikan di Indonesia, sebenarnya bisa dikaji beberapa pikiran atau konsep tentang Pendidikan di Indonesia, yang mungkin dapat dipergunakan sebagai Referensi minimal untuk memperolah gambaran tentang teori-teori mendidik yang berakar dari budaya Nasional.

Dari beberapa Pendiri Sekolah- sekolah di Indonesia,seperti Sekolah Adhi Darma, Institut Kayu Tanam, Taman Siswa, Sekolah Kartini,dan mungkin ada sekolah- sekolah lain yang dapat dikaji adanya ide- ide dasar yang bersumber budaya dalam melaksanakan/ mengelola Pendidikan. Ide- ide tersebut dapat kita kategorikan berciri teoritik dan pratek,baik untuk pendidikan tingkat mikro, maupun makro.

Ide/konsep dari para pendiri (yang saat ini bisa dinamakan MISI dan VISI) jelas dinyatakan pada awal pendirian Sekolah- sekolah tersebut. Namun tetap tidak bisa diingkari adanya pengaruh "situasi" ketika itu yaitu situasi "Penjajahan" oleh kolonial Belanda. Sehingga "nilai- nilai" ketika itu bersemangat 
kemerdekaan,membebaskan generasi muda Indonesia dari ketergantungan pada kaum penguasa/ Penjajah.

Strategi Pendidikan yang dilaksanakan disekolah- sekolah ada berbagai cara. Mulai dari menanamkan harga diri dengan melengkapi ketrampilan anak- anak muda supaya bisa hidup mandiri (MoH. SyAFII), menolak bantuan/kerja sama dengan Pemerintah Belanda dalam mengelola Pendidikan serta mengimbangi budaya Barat dengan pengembangan kelestarian budaya bangsa (Ki Hajar Dewantara, Adhi Darma).

Dalam tulisan ini, lingkup penulisan dibatasi terutama karya-karya KI HAJAR DEWANTARA dengan tekanan pada aspek budaya Jawa, yang semuanya bersifat normatip. Karya-karya beliau yang berupa pedoman mendidik dengan dasar budaya/ tradisi (Jawa). Banyak semboyan-semboyan yang dipergunakan sebagai dasar mengimbangi Budaya Barat yang masuk langsung atau tidak, dalam lingkaran budaya di Indonesia.

Maksud dari tulisan ini seperti disebut diatas, membahas sederhana apa dan bagaimana ajaran- ajaran tersebut "mengurangi" nilai/ norma Barat yang berciri Individualistik, Rasionalistik, intelektualistik, dan lain- lain dengan menggunakan ide- ide, konsep- konsep, nilainilai budaya nasional.

\section{PENGEMBANGAN NILAI BUDAYA NASIONAL}

Dari apa yang diajarkan Ki Hajar Dewantara dalam menyelenggarakan TAMAN SISWA, ada beberapa semboyan sebagai pedoman opersional. yang berasal dari nilai- nilai budaya Jawa. Dengan tegas dinyatakan bahwa ciri mendasar Pendidikan Taman Siswa adalah "Kultural Nasional" yang berarti bahwa orientasi pendidikan/ pembelajaran adalah budaya nasional (RAHARJO, 2009).

Kata "Taman Siswa " itu sendiri sudah memiliki arti "suatu tempat belajar yang hijau/ indah/ damai, yang dihuni oleh para Guru dan
Murid, sebagai suatu keluarga" (ibid, 2009).

Kesemuanya diharapkan menjaga / melestarian nilai budaya "adiluhung", warisan generasi pendahulu yang diyakini membawa kedamaian (ibid, 2009). Pengertian ini, tidak diartikan sebagai nilai yang tertutup, namun sebagai dasar pengembangan nilai- nilai dalam kebudayaan dan Pendidikan. Juga dapat diartikan sebagai dasar pertimbangan "kolaborasi/adopsi" terhadap nilai luar yang dapat memperkaya budaya daerah, tanpa terjadinya "gesekan" nilai Budaya kita sendiri.

Secara jelas, pada Taman Siswa dibekali dengan tujuh Asas Pokok: (1) Kemerdekaan,(2) Metoda AMONG, (3) berperadaban bangsa sendiri, (4)pendidikan yang merata, (5) mandiri, (6) sederhana dan, (7) makarya. Dan kesemuanya ini didasari rasa ikhlas, suci, dengan semangat kekeluargaan yang luhur. Serta ditampilkan dalam perilaku yang utuh, Asas- Asas tersebut berkembang dari beberapa "semboyan" normatip (dalam Bahasa Jawa).

1. Semboyan TRI HAYU (tiga pedoman/ hayu) yaitu "MEMAYU HAYUNENG SARIRO, MEMAYU HAYUNING BONGSO, MEMAYU HAYUNING BAWONO”. Maksudnya Pendidikan harus mengarah pada kemanfaatan diri sendiri, kemanfaatan bangsa, dan kemanfaatan alam semesta. Hal ini berbeda dengan tekanan pada individualistik yang hanya "SARIRO" kurang memperhatikan faktor- faktor lainnya, seperti kepentingan bangsa dan alam lingkungan. Itu menyebabkan terbentuknya kurang sempurna.

2. Sembonyan TELU MONG (tiga hubungan sikap) memelihara manusia yang meliputi $M O M O N G, A M O N G$ dan, NGEMONG. Pernyataan ini semua berarti Pendidik tidak terpisah, tapi menyatu dalam jiwa memelihara dengan rasa kekeluargaan yang tinggi (Mong). Guru adalah seorang $P A M O N G$ yang mempunyai kesabaran dan rasa kasih sayang sebagai orang tua, memelihara/ mengasuh siswa yang DIEMONG 
seperti dalam satu keluarga. Metoda ini adalah suatu proses pendekatan pribadi, yang menganggap siswa yang DIEMONG adalah subyek yang tidak lain adalah keluarga (seperti anak) sendiri. Keluarga Jawa adalah satu kesatuan yang bulat dalam satu sistem, yang berdasar ikatan keturunan dan bathin yang erat. Sebagai kesatuan manusia, maka unitunit tersebut memiliki kemampuan berbeda- beda dan watak- watak tertentu. Namun sama sekali berbeda dengan ide mekanistik yang menganggap siswa seperti mesin/ robot yang dapat dibuat sesukanya seperti "Teori Tabula Rasa".

3. TRINGA Seorang guru yaitu PAMONG memiliki 3 sasaran dalam menanamkan pengetahuan kepada siswa melalui (1) NGERTI,(2) NGROSO, (3) NGELAKONI. Juga digunakan 3 sifat: Cipta, Rasa dan Karsa yang mungkin sedikit berbeda dngan kognitif, afektif, dan psikomotorik ( B. S. Bloom) Perbedaan terletak pada "NGEROSO" artinya memahami dengan sungguh- sungguh dan penuh kesadaran, karena seperti "memasuki" dan "berintegransi"/ menjiwai kedalam dunia pengetahuan itu sendiri.

4. Semboyan: "ING NGARSA SUNG TULADA, ING MADYA MANGUN KARSA, TUT WURI HANDAYANI" semboyan ini cukup terkenal secara $\mathrm{Na}$ sional. Ini berarti para Guru atau Pamong memberikan perhatian pada siswa bagaimana keadaan siswa, karena di situlah letak "posisi" PAMONG atau Guru. Disini pula mengandung pengertian bahwa guru sebagai PAMONG memiliki kopetensi moral sabagai bawaan rasa cinta atas dasar kebenaran Riligius/ Kultural. Semua terwujud dalam 3(tiga) peran/ kegiatan Guru. Ke 3 peran Guru tersebut (1). Untuk Kelompok Siswa yang perlu/ butuh mendapatkan contoh- contoh dari Guru, (2). Untuk Kelompok Siswa yang sudah mengerti hanya perlu didampingi/ diberi motivasi, (3). Kelompo Siswa yang sudah mampu berdiri sendiri diikuti dari belakang.
5. Masih banyak lagi semboyan-semboyan kultural yang dipergunakan oleh KI HAJAR Dewantara. Yang berdasar unsur kulutur (Jawa), a.l.

a. LAWAN SASTRA NGESTI MULYA. bahwa ilmu akan membawa kebajikan dan kesejahteraan Manusia, bukan sebaliknya. Pendidikan manusia (Indonesia) mengutamakan Etika dan Moral yang tinggi tentang keilmuan.

b. SASTRA HERDJENDRAJUNINGRAT PANGRUWATING DYU artinya ilmu yang luhur/ bermutu akan dapat menyelamatkan peradapan dunia. Ini juga berarti pendidikan hendaknya memiliki ilmu- ilmu yang luhur tersebut.

c. SUCI TATA NGESTI TUNGGAL Pendidikan harus mempunyai ilmu yang benar dan suci untuk di amalkan kepada bangsa dengan bertakwa kepada Tuhan. Ilmu yang tidak membawa berkah dengan peningkatan martabat manusia (aspek Aksiologis), tidak boleh disampaikan kepada generasi muda/ dan kesemuanya harus kembali pada dasar- dasar keTuhanan yang Maha Esa.

d. TETEP, MANTEP, ANTEP, artinya pendidikan harus konsisten percaya diri, teguh imandan berbobot untuk mencapai hasil pendidikan yang luhur. Tujuan mendidik anak harus tegar, konsisten dalam menghadapi Pendidikan Negatip di masyarakat.

e. NGANDEL, KENDEL, BANDEL, KANDEL, ini berarti bahwa pendidikan harus berkualitas dan dapat di percaya yang di ikuti dengan keberanian dan ketegasan yang mantap.

f. NENG-NING-NUNG-NANG ini adalah gambaran dari proses dan strategi pendidikan yang harus tenang, jernih, kuat, dan pasti dalam arti fokus pada obyek/ akan memberi hasil yang memuaskan (SUPARTO RAHARJO, 2009). 
Seperti disebut didepan, ajaran-ajaran Ki Hajar Dewantara yang berciri kejawaan. Dalam masyarakat Jawa ada filsafat Jawa berciri MONO-PLURALISTIK SIPKRETIK. Artinya budaya Jawa mengenal berbagai pengaruh dari luar antara lain budaya Hindu, Budha, dan Islam termasuk pengaruh Alam sekitar. Orang Jawa pada masa- masa yang silam adalah petani dan nelayan. Itu berarti, mereka sangat tergantung dan menjadi satu dengan alam (Heniy AstiyanTO, 2006).

Karena kedekatan hidup dengan alam, maka hidup masyarakat Jawa banyak memiliki mitos, sebagai metode untuk menghadapi dan menjawab gejala alam sekelilingnya, seperti: Dewi Sri, Nyai Lorokidul, dan lain- lain.

\section{BEBERAPA DASAR BUDAYA JAWA}

Disamping banyaknya semboyan-semboyan tersebut ada juga pedoman-pedoman yang didapat dari pikiran- pikiran makro mikro kultural.

1. KODRAT ALAM menjadi dasar hakekat manusia tentang hidup dialam semesta. KODRAT ALAM, adalah Faktor Eksternal yang tidak bisa diabaikan. Dan hal ini disebut berkali- kali oleh Ki HaJAR DEWANTARA. Anak-anak kita bahkan manusia tergantung pada kodratnya. Alam Kosmos berbicara tentang kodrat manusia, dalam arti Makro maupun dalam tingkat Mikro.Manusia adalah makluk yang berada dialamnya, dan kesempurnaan hidup dicapai dengan kesadaran akan kodratnya. Tidak boleh melampoi kodratnya

2. ALAM "BERBULATAN" (HeNLY AstiYANTO, 2006) artinya manusia hidup dalam "KEBULATAN ALAM", Yaitu: bahwa Alam terdiri dari bahan Alam diri, Alam kebangsaan dan Alam kemanusiaan, ke 3 komponen "alam" tersebut yang berpengaruh terhadap kehidupan manusia secara utuh. Keseluruhan tersebut harus dikelola secara harmonis, seimbang, dan serasi ke- mampuan dan pendidikan yang tidak memiliki criteria tersebut menciptakan anak- anak yang tidak berkembang kedua utuh. Sejalan dengan hal- hal tersebut, orang Jawa juga punya kepercayaan yang sangat kuat kepada "Sangkan Paraning Dumadi" yaitu sang Maha Pencipta (TUHAN YANG MAHA ESA) banyak ugeran- ugeran (amsal/ ajaran- ajaran) yang terkait dengan unsur religius tersebut. Dan ugeran- ugeran tersebut jika disimak akan ditemukan butir- butir dari Budaya Jawa, Kesemuanya dinyatakan dengan bahasa Jawa, terkait dengan kegiatan Pendidikan.

3. "SING NGERTI SUBO SITA LAN DUGA PRAYUGO", (Henly Astiyanto, hal 21) artinya anak- anak kita harus diajari tata karma, santun,sesuai dengan keadaan, dan dengan siapa anak- anak tersebut bergaul (Etika Komunikasi). Belajar mengetahui "siapa dirinya" adalah kesantunan yang penting adalah pergaulan.

4. ADA 5 HAL yang harus dihormati (Wulang Reh Paku Buwono IV). Yang pertama, AyahIbu, kedua Mertua, ketiga Saudara Tua, keempat Guru, kelima TUHAN YANG MAHA ESA. Jelas ini adalah pendidikan moral yang mulai banyak diabaikan. Nilainilai semacam itu sulit didapatkan pada dunia Barat, yang serba rasional dan individual. Bahkan kaum intelektual di Indonesia juga cenderunglupa akan nilai- nilai luhur tersebut, (Henly Astiyanto, 2006) Sering orang tua pada saat ini bersikap sebagai "teman/ sama tinggi" dengan anak- anaknya. Hal ini rasanya akan dapat mengurangi kwalitas hubungan dengan orang tua tersebut. Betapapun orang tua adalah "tetua" yang menjadi pusat tuntunan anak- anaknya dan dihormati sebagai orang yang berwibawa. Bukan sekedar "Teman seangkatan" saja.

5. Ada beberapa upacara- upacara ritual terkait dengan perkembangan hidup manusia dan alam yang dipercaya membawa ketenangan/ keamanan jiwa raga. Sebagai orang Jawa, 
seperti upacara- upacara. antara lain: "Tedak siti” (turun ketanah bagi anak- anak yang mulai bisa berjalan. (KoENTJARANINGRAT. 1967). "Ngnuwat" (memohon keselamatan) terutama untuk anak- anak yang memiliki kelahiran tertentu. "Ngrasuki" (mengirim doa bagi yang sudah meninggal dunia). "Midodareni" (calon mempelai perempuan Wajib "disimpan", tidak boleh keluar/ bertemu dengan calon mempelai laki- laki, karena seperti bidadari yang suci datang dari langit). Dan masih banyak lagi tata cara (upacara ritual) yang menjadi unsur Budaya Jawa.

\section{PENUTUP}

Dari uraian- uraian di atas, jelas ajaran- ajaran Ki Hajar Dewantara sangat akrab dengan dasar- dasar Filosofis Jawa. Masih banyak lagi ajaran- ajaran Jawa yang dapat ditemukan, yang langsung atau tidak berpengaruh pada pikiranpikiran Ki Hajar Dewantara. Pengaruh alam sangat besar dan semuanya ditunjukan pada pengembangan karakter budaya generasi muda, baik secara Makro maupun Mikro.

Semangat yang menonjol adalah menolak secara halus ajaran Barat dengan menekan pada ajaran- ajaran kesantunan, kekeluargaan, mengatur dengan Alam (Kodrat Alam), dan lain- lain. Karena Etika Jawa bertumpu pada "NGESTI PRIBUDI", tidak individual dalam arti tidak egois (DAMANJATI Supajar 1943) Sifat- sifat seperti individralistik,rasionalistik, dan lain- lain diimbangi dengan semangat ajaran ke Jawaan. Demikian, semoga tulisan ini bisa bermanfaat.

\section{DAFTAR PUSTAKA}

AdHI, Aribowo Suprajitno.

2009 Sang Guru. Jakarta: Alex Media Kom putindo.

Astiyanto, Heniy.

2006 Filsafat Jawa: Menggali Butir- Butir Keari fan Lokal. Yogyakarta: Wasta Pustaka.
Degeng, I Nyoman SudAna.

2007. Paradigma Baru Pembelajaran Untuk. Menumbubkan Life Skill Diera

Otonomi Daerah.

Harahap, H.A.H. \& B.S. Dewantara.

1980. Ki Hajar Dewantara. Jakarta: Gunung Agung.

KOENTJARANINGRAT.

1974. Kebudayaan Mentalitet dan Pembangu nan. Jakarta: Gramedia.

RAHARDJO, SUPARTO.

2009. Ki Hajar Dewantara: Biografi Singkat. Jogjakarta: Garasi.

Soeratman, Darsiti, Ki Hajar Dewantara, Dep Diknas, DiREKTORAT.

1989. Sejarah dan Nilai Tradisional. Jakarta.

WIRYOKUSUMO, ISKANDAR.

2010. Teori-teori belajar sekitar Ajaran Ki Hajar Dewantara, Tut Wuri Handayani. Pidato Pengukuran Guru Besar. Surabaya. 